Check for updates

Cite this: RSC Adv., 2019, 9, 36815

Received 7th October 2019

Accepted 4th November 2019

DOI: 10.1039/c9ra08133j

rsc.li/rsc-advances

\section{Effect of polyvinyl acetals on non-isothermal crystallization behaviour and mechanical properties of poly( $\varepsilon$-caprolactone)}

\author{
Biao Yang, (D) * Xin Zhang, Chun Wang, Ran Liu, Baomin Fan, ${ }^{*}$ Huijuan Zhang (D) \\ and Hui Sun 1 D
}

Polyvinyl acetaldehyde (PVAC) and polyvinyl butyral (PVB), as nucleating agents, were melt mixed with poly( $\varepsilon$-caprolactone) (PCL), and the non-isothermal crystallization behavior and crystalline morphology of PCL was characterized using differential scanning calorimetry (DSC) and polarizing microscopy (POM). It was found that melt shearing made the crystallinity of control PCL increase from $37.94 \%$ (as-received) to $41.15 \%$ and the crystallization temperature raised by $7.7^{\circ} \mathrm{C}$. As the mass fraction of polyvinyl acetals increased from $0.1 \mathrm{wt} \%$ to $10 \mathrm{wt} \%$, both crystallization temperature and crystallinity of PCL were decreased; the spherulite size of PCL was increased from a few microns to $200 \mu \mathrm{m}$ and a fast cooling procedure facilitated the homogeneity of spherulite size. When the content of nucleating agent was less than $1 \mathrm{wt} \%$, no obvious microphase separation was observed under scanning electron microscopy; the tensile strength, yield strength and elongation at break of PCL increased slightly; and the Young's modulus of PCL was improved by $67 \%$ at a 0.1 wt $\%$ mass fraction of PVB which is beneficial to PCL in high load bearing applications. When the contents of nucleating agents were higher than $1 \mathrm{wt} \%$, the microphase separation occurred obviously and a large amount of fine spherulites appeared with the deterioration of mechanical properties. The modified Avrami and Tobin models could well describe the non-isothermal crystallization kinetics.

\section{Introduction}

As an aliphatic polyester with excellent toughness and biocompatibility, poly( $\varepsilon$-caprolactone) (PCL) has been widely used in biomedical fields, ${ }^{1-3}$ such as a carrier for drugcontrolled release, ${ }^{4-8}$ cell culture substrate, ${ }^{3,9}$ scaffold. ${ }^{10-12}$ However, the nature of fast crystallization behaviour made PCL disadvantageous in the field of rapid degradation and high load bearing applications. Therefore, how to improve the final properties of PCL by regulating the crystallization behaviour has attracted more attention.

Based on molecular design, the crystallization behaviour of PCL can be tailored by copolymerization with flexible or rigid segments. The reported copolymer components include poly(lactic acid), ${ }^{13-18}$ polyethylene glycol, ${ }^{19-21}$ polystyrene, ${ }^{22}$ polyvinylpyrrolidone, ${ }^{23} \quad$ poly(hydroxybutyrate-cohydroxyvalerate), ${ }^{24,25}$ and so on. In most cases, the crystallization nature of PCL was retarded after copolymerization resulting a decreased crystallinity of PCL segment. For example, the crystallinity of PCL segment decreased from $54.7 \%$ to $2.2 \%$ in

School of Materials Science and Mechanical Engineering, Beijing Technology and Business University, Beijing 100048, P. R. China. E-mail: ybiao@btbu.edu.cn; fanbaomin@btbu.edu.cn the six-armed star-shaped poly( $\varepsilon$-caprolactone)- $b$-poly(D,L-lactide-co-glycolide). ${ }^{26}$

Small molecules, macromolecules and nanoparticles were also used as nucleating agents to influence the crystallization behaviour of PCL and the effects were quite different. Generally, the addition of nucleating agent can increase nucleation density resulting in smaller grain size and higher crystallization temperature. For instance, after incorporating with cyanuric acid $(0.2 \mathrm{wt} \%)^{27}$ and $\alpha$-cyclodextrin inclusion complex $(\alpha \text {-CD-IC })^{28,29}$ by solution casting, the non-isothermal crystallization temperature of PCL, overall isothermal melt crystallization rate, and nucleation density of PCL spherulites were improved. Carbon nanotubes, ${ }^{30,31}$ attapulgite $(0.5-7 \mathrm{wt} \%)^{32}$ and pristine nanocrystalline cellulose $^{33}$ act as heterogeneous nucleating agent, promoted the crystallization rate, and increased the non-isothermal crystallization temperature by $10-16{ }^{\circ} \mathrm{C}$. The spherulite size of isothermally crystallized PCL decreased from nearly $200 \mu \mathrm{m}$ to a few microns. Meanwhile, the crystallinity increased slightly. ${ }^{31}$ Although the particle size is much larger than nano-scale, basalt fibers with a diameter of 7-15 $\mu \mathrm{m}$ and average length of $5 \mathrm{~mm}$ still show excellent nucleation effect. The non-isothermal crystallization temperature of PCL was raised by $10{ }^{\circ} \mathrm{C}$, and the crystallinity was increased from $38 \%$ to $45 \% .^{34}$

Contrary to what was mentioned above, although benzoxazine (10-50 wt\%) was miscible with PCL but the non-isothermal 
crystallization temperature and isothermal crystallization rate of PCL were decreased. ${ }^{35}$ Moreover, when macromolecules were blended with PCL at high mass fraction, the nucleation effect was weakened due to the mobility constraints. Cai et al. found that thermoplastic starch (TPS) (ratios of TPS/PCL were higher than 2/ 10), had a restrain effect on the isothermal crystallization of PCL and resulted in a decreased crystallinity. ${ }^{36}$

The content of highly effective nucleating agent is preferably less than 1-2 wt\%, and excessive dosage will affect the inherent properties of the substrate. In our previous works, we found that polyvinyl butyral (PVB) (less than $1 \mathrm{wt} \%$ ) was an efficient macromolecular nucleating agent for biodegradable polyesters, such as poly(butylene succinate) (PBS) ${ }^{37}$ and poly(butylene succinate-co-terephthalate) (PBST). ${ }^{38}$ The spherulite size of PBS and PBST was reduced to several microns and the crystallization temperature was increased by $10{ }^{\circ} \mathrm{C}$. Therefore, polyvinyl acetals are supposed to be effective nucleating agent of PCL. However, the few relevant reports of PCL/PVB based composite ${ }^{\mathbf{3 9 4 0}}$ and blend $^{41}$ with a PVB content higher than 2 wt $\%$, which were based on solution casting process, are all focused on the isothermal crystallization behaviour and the banded spherulite. Non-isothermal crystallization is closely related to the forming process of PCL, which directly determines the crystalline morphology, biodegradation rate and mechanical properties of the final product. In this work, we prepared the blends of PCL with the content of polyvinyl acetals from $0.1 \mathrm{wt} \%$ to $10 \mathrm{wt} \%$, and revealed the effect of polyvinyl acetaldehyde (PVAC) and PVB on the non-isothermal crystallization behaviour, crystalline morphology and mechanical properties of PCL.

\section{Experimental}

\section{Materials}

Poly ( $\varepsilon$-caprolactone) with a molecular weight of $8 \times 10^{5} \mathrm{~g} \mathrm{~mol}^{-1}$ (CAPA 6800) was purchased from Solvay, USA. The self-made PVAC and PVB have the same polymerization degree of 1700 , and the content of acetal group are $84 \%$ and $78 \%$, respectively. The structures of PVAC and PVB are illustrated in Fig. 1.

\section{Sample preparation}

PCL and polyvinyl acetals were dried in a vacuum oven at $50{ }^{\circ} \mathrm{C}$ for $8 \mathrm{~h}$ prior to melt mixing. PVAC and PVB were dissolved in

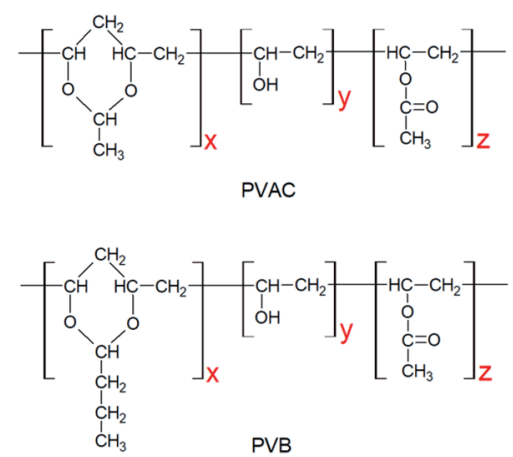

Fig. 1 Molecular structures of PVAC and PVB. alcohol to obtain a $10 \mathrm{wt} \%$ solution, then the solution was mixed with the PCL granules. After being dried at $50{ }^{\circ} \mathrm{C}$ for $8 \mathrm{~h}$, the mixture was blended in a torque rheometer (XSS-300, Shanghai Kechuang Rubber \& Plastic Machinery Co. Ltd., China) at $100{ }^{\circ} \mathrm{C}$ and $50 \mathrm{rpm}$ for $8 \mathrm{~min}$. As-received PCL was mixed under the same conditions as the control sample. The result materials were cut into small particles and oven-dried at $50{ }^{\circ} \mathrm{C}$ for $8 \mathrm{~h}$. The standard type $5 \mathrm{~A}$ dumbbell shaped specimens (GB/T 1040.2-2006/ISO 527-2-1993) were prepared by injection moulding (MiniJet Pro, Thermo Fisher Scientific, USA) at a cylinder temperature of $100{ }^{\circ} \mathrm{C}$ and a mould temperature of $25{ }^{\circ} \mathrm{C}$; the injection pressure is 500 bar and the pressure holding time is 20 seconds. All the specimens were conditioned at room temperature (about $25{ }^{\circ} \mathrm{C}$ ) for $48 \mathrm{~h}$, followed by mechanical properties test and differential scanning calorimetry analysis.

\section{Characterization}

All mechanical properties were examined using an electronic universal testing machine (CMT6104, Shenzhen Xinsansi Metrology Technology Co. Ltd., China) at a tensile rate of 70 $\mathrm{mm} \mathrm{min}^{-1}$. The final values were averages of at least five specimens.

The non-isothermal crystallization behaviour was analysed by differential scanning calorimeter (Q20, TA Instruments Inc.) under nitrogen atmosphere. Initially, the samples of 5-10 mg were firstly rapidly heated to $110^{\circ} \mathrm{C}$ and maintained for $5 \mathrm{~min}$ to eliminate the heat history; subsequently, samples were cooled to $-20{ }^{\circ} \mathrm{C}$ at a cooling rate of $10{ }^{\circ} \mathrm{C} \mathrm{min}{ }^{-1}$ and held for $5 \mathrm{~min}$, then the temperature raised to $110{ }^{\circ} \mathrm{C}$ at a heating rate of $10{ }^{\circ} \mathrm{C} \mathrm{min}^{-1}$. The relative crystallinity during the cooling process $\left(X_{\mathrm{c}}\right)$ can be calculated according the eqn (1).

$$
X_{\mathrm{c}}=\frac{\Delta H_{\mathrm{c}}}{W_{\mathrm{A}} \times \Delta H_{\mathrm{m}}^{0}} \times 100 \%
$$

where $W_{\mathrm{A}}$ is the mass fraction of PCL; $\Delta H_{\mathrm{c}}$ is the crystallization exothermic enthalpy during the program cooling process; $\Delta H_{\mathrm{m}}^{0}$ is the melting enthalpy of PCL with $100 \%$ crystallinity, $139.5 \mathrm{~J} \mathrm{~g}^{-1}$. $^{42}$

The crystallinity of PCL during the heating process $\left(X_{\mathrm{c}}^{*}\right)$ is calculated according to the eqn (2).

$$
X_{\mathrm{c}}^{*}=\frac{\Delta H_{\mathrm{m}}}{W_{\mathrm{A}} \times \Delta H_{\mathrm{m}}^{0}} \times 100 \%
$$

where $\Delta H_{\mathrm{m}}$ is the melting endothermic enthalpy.

The crystalline morphology was observed under a polarizing optical microscope (Olympus BX51) equipped with a heating stage (THMS600, Linkam Scientific Instrument Ltd.). Samples sandwiched between two glass slides were heated to $110{ }^{\circ} \mathrm{C}$ and kept for $3 \mathrm{~min}$ to eliminate any thermal history, then the melt was cooled to $22{ }^{\circ} \mathrm{C}$ at a rate of $10{ }^{\circ} \mathrm{C} \mathrm{min}^{-1}$ and POM micrographs were recorded. To obtain the crystalline morphology of injection moulded (rapidly cooled) PCL, samples used for POM observation undergone cooling conditions similar to those experienced during injection. After eliminating thermal history as mentioned above, the set of slides and clamped sample was 

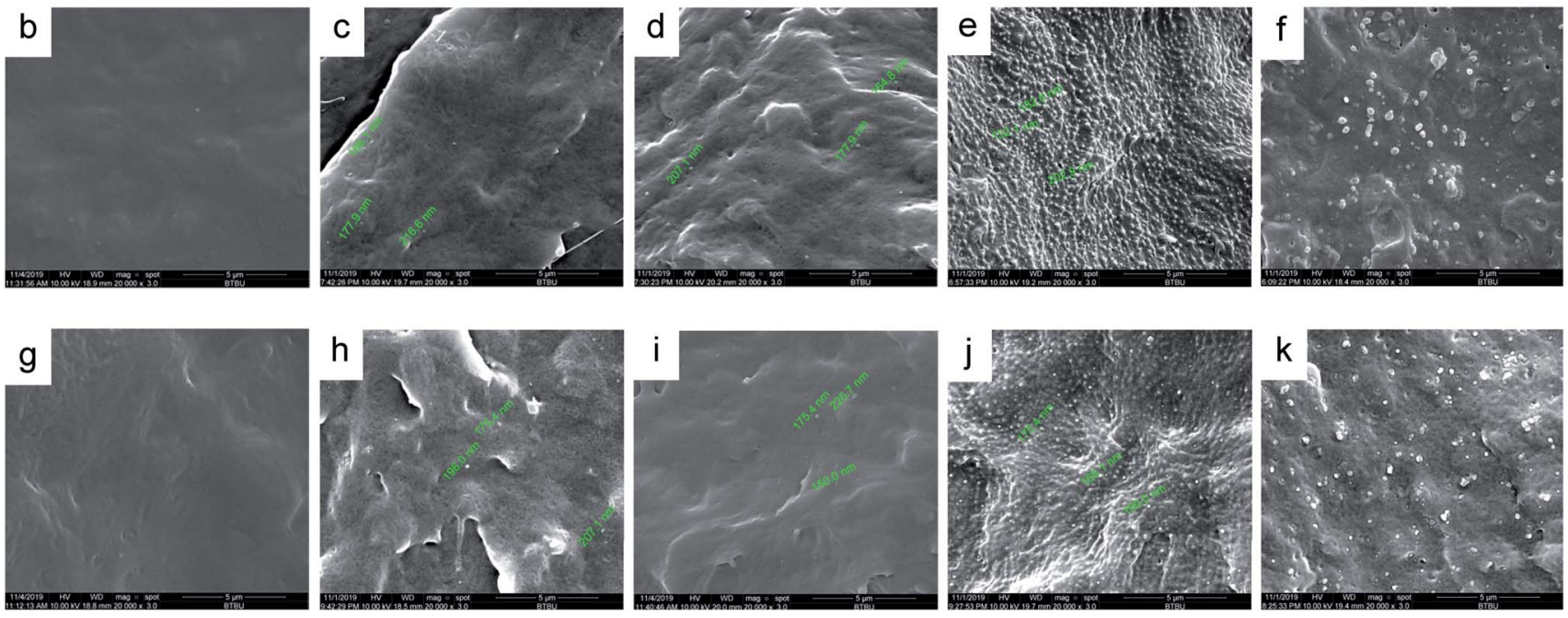

Fig. 2 SEM photomicrographs for the fractured morphology of PCL blends. (a) Control PCL; (b)-(f) PCL with 0.1 wt\%, 0.3 wt\%, 0.7 wt $\%, 1.0$ wt\% and $10.0 \mathrm{wt} \%$ PVAC; (g) -(k) PCL with $0.1 \mathrm{wt} \%, 0.3 \mathrm{wt} \%, 0.7 \mathrm{wt} \%, 1.0 \mathrm{wt} \%$ and $10.0 \mathrm{wt} \%$ PVB.

quickly moved into a $25{ }^{\circ} \mathrm{C}$ water bath for $10 \mathrm{~min}$ before POM observation at room temperature.

The microphase separation of PCL blends was observed on scanning electron microscope (SEM, Quanta FEG 250, FEI Company). The samples for SEM analysis were brittle fractured after cooling in liquid nitrogen, and the images of fracture surface were obtained under an accelerating voltage of $10 \mathrm{kV}$.

\section{Results and discussion}

\section{Compatibility of PCL/polyvinyl acetals}

Two polyvinyl acetals with different side groups, PVAC and PVB, as shown in Fig. 1, were used as macromolecular nucleating agents to regulate the crystallization behaviour and crystalline morphology of PCL. Due to the melting temperature of PCL is about $60{ }^{\circ} \mathrm{C}$, which overlaps with the glass transition temperature of PVB and PVAC, neither DSC nor dynamic mechanical analysis (DMA) can directly characterize the compatibility of the blending system. Therefore, SEM was employed to observe the microphase separation in the blends and the microphotographs are shown in Fig. 2 .

When the content of nucleating agent was less than $1 \%$, nanoparticles of PVAC and PVB seldom appeared in the field of view, indicating that the system had good compatibility. While at nucleating agent dosage of $1 \%$ (Fig. $2 \mathrm{~d}$ and i), obvious microphase separation occurred, nanoparticles of PVAC and PVB with a size of 150-200 nm were densely dispersed in PCL matrix. With the further increase of the dosage (10 wt\%), the particle size of polyvinyl acetals increased obviously, indicating that the compatibility became poor.

\section{Effect of polyvinyl acetal on crystallization behaviour of PCL}

Although the molecular structures of PVAC and PVB are different, their effects on the crystallization behaviour of PCL are similar. From the DSC curves (Fig. 3) and the crystallization parameters (Table 1 ) of the PCL and PCL/acetal blends, we found a very unusual phenomenon, i.e., simply mixing made the crystallinity of control PCL increased from $37.94 \%$ (asreceived) to $41.15 \%$ and the crystallization temperature $\left(T_{\mathrm{c}}\right)$ raised by $7.7{ }^{\circ} \mathrm{C}$. The undercooling degree, $T_{\text {onset }}-T_{\mathrm{c}}$, is only $2.52{ }^{\circ} \mathrm{C}$, which is significantly lower than other samples, indicating that the crystallization rate is improved dramatically. This phenomenon can be explained by carding effect induced by melt shearing. ${ }^{43}$ The intertwisted chains of as-received PCL are partly disentangled during mixing, and thus the chain's spatial freedom was improved, which is favourable for crystallization. As a consequence, the crystallization rate and crystallinity are improved.

Furthermore, incorporating acetals decreased the crystallization temperature of PCL. Compared with the as-received PCL, $T_{\mathrm{c}}$ of samples with $10 \mathrm{wt} \%$ PVAC and $10 \mathrm{wt} \%$ PVB decreased by $9.04{ }^{\circ} \mathrm{C}$ and $10.65{ }^{\circ} \mathrm{C}$, respectively. Meanwhile, the as-received and acetal-added samples have a similar undercooling degree. This suggests that the crystallization ability of PCL is weakened, which needs to crystallize at a lower temperature. In spite of 
Table 1 Crystallization parameters derived from DSC data

\begin{tabular}{|c|c|c|c|c|c|c|c|c|c|c|}
\hline PCL sample & \multicolumn{5}{|c|}{ PCL/PVAC } & \multicolumn{5}{|c|}{ PCL/PVB } \\
\hline As-received & 19.51 & 37.94 & 6.34 & 56.8 & 38.93 & 19.51 & 37.94 & 6.34 & 56.8 & 38.93 \\
\hline Control & 27.21 & 41.15 & 2.52 & 54.8 & 40.95 & 27.21 & 41.15 & 2.52 & 54.8 & 40.95 \\
\hline $0.1 \%$ acetal & 15.21 & 40.28 & 5.99 & 53.33 & 38.91 & 15.01 & 37.30 & 4.26 & 54.85 & 38.67 \\
\hline $1.0 \%$ acetal & 11.71 & 35.40 & 6.77 & 55.27 & 34.74 & 10.68 & 36.57 & 6.07 & 55.06 & 35.33 \\
\hline $5.0 \%$ acetal & 12.60 & 34.49 & 5.29 & 54.83 & 35.39 & 9.89 & 32.99 & 6.53 & 54.16 & 35.37 \\
\hline $10.0 \%$ acetal & 10.47 & 32.00 & 7.25 & 55.21 & 36.46 & 8.86 & 33.03 & 6.48 & 53.53 & 34.24 \\
\hline
\end{tabular}

this, the crystallinity has just a slight drop, and the minimum value of $X_{\mathrm{c}}^{*}$ appeared at $0.7 \mathrm{wt} \%$ content of polyvinyl acetals. It can be understood from the difference of glass transition temperature $\left(T_{\mathrm{g}}\right)$ between polyvinyl acetals and PCL. PVAC and PVB act as macromolecular nucleating agents with a $T_{\mathrm{g}}$ of $50-$ $60^{\circ} \mathrm{C}$, which is much higher than that of pristine PCL $\left(-60^{\circ} \mathrm{C}\right)$. During the cooling process, the molecular chains of polyvinyl acetals were frozen firstly and acted as heterogeneous nucleating centres to induce crystallization via hydrogen bond between hydroxyl group on acetal chains and ester groups of PCL as well as the steric effect of side chains of acetal group, meanwhile entanglement between polyvinyl acetals and PCL restricting the rearrangement of flexible PCL chains.

\section{Effect of polyvinyl acetal on crystalline morphology of PCL}

To gain insight into the nucleating effect of acetals, we observed the crystalline morphology through POM. Fig. 4 shows the polarized photomicrographs of the program cooling samples (they were kept at $110{ }^{\circ} \mathrm{C}$ for $3 \mathrm{~min}$, then cooled to room temperature at $10{ }^{\circ} \mathrm{C} \mathrm{min}^{-1}$ ), which presents the evolution of crystal morphology of PCL.

Nucleating agent usually increases the nucleation density and reduces spherulite size, and thus elevates the crystallization rate and/or crystallinity. ${ }^{27,34,44,45} \mathrm{POM}$ observation indicates that control PCL has a uniform small grain size $(5-10 \mu \mathrm{m})$ (Fig. 4a). However, polyvinyl acetals (less than $1 \mathrm{wt} \%$ ) increase the spherulite size of PCL to 170-220 $\mu \mathrm{m}$ (PVAC) and 160-200 $\mu \mathrm{m}$
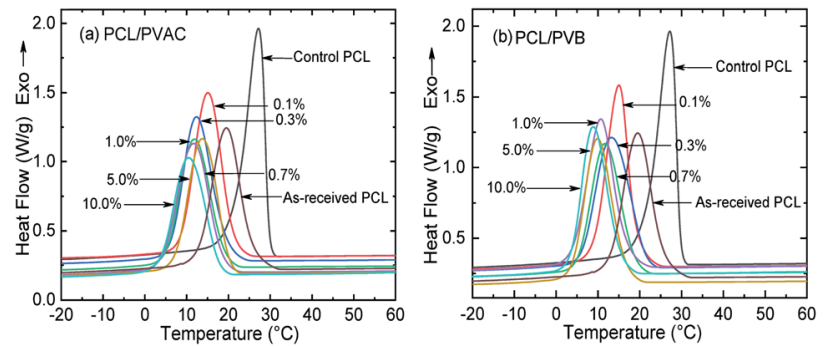

Fig. 3 DSC curves of (a) PCL/PVAC and (b) PCL/PVB blends under a cooling rate of $10^{\circ} \mathrm{C} \mathrm{min}^{-1}$.
(PVB), as well as measly fine grains appear in the field of view. The sample of $1 \mathrm{wt} \%$ PVB (Fig. 4j) visualizes that the large spherulite dominated the crystallization and fine grains disappeared completely. When the content of polyvinyl acetals beyond $1 \mathrm{wt} \%$, some fine grains with the similar size as control PCL appear again, and "large" spherulites with different size coexisted.

The increase of spherulite size mainly depends on the unique molecular nature of PCL, extremely low glass transition temperature and excellent flexibility of aliphatic polyester, as well as the competition between self-nucleation of PCL and heterogeneous nucleation of acetals. At lower acetal content (less than $1 \mathrm{wt} \%$ ), PVB and PVAC are miscible with PCL and the heterogeneous nucleation of acetals suppresses the homogeneous self-nucleation of PCL. With the increases of acetal content (greater than $1 \mathrm{wt} \%$ ), as a result of compatibility deterioration, chain clustering of acetals even phase separation occurred easily. Accordingly, the nucleation density decreased and the distribution of nucleation centers was non-uniform, which is helpful to self-nucleation of PCL.

Nucleation induced grain sizes growing-up during nonisothermal crystallization is similar with reports of isothermal crystallization, ${ }^{39,41,46}$ whereas no banded spherulites of PCL have been observed, which generally appeared at higher temperatures and longtime crystallization.

\section{Mechanical properties of PCL}

Generally, the mechanical properties of PCL depend to a large extent on the microstructure and morphology. Therefore, controlling the content of amorphous and crystalline phase in a semicrystalline polymer offers the final desired properties.

There are three stages during the stretching of PCL (Fig. 5a and b) i.e. elastic zone, cold drawing, stress hardening. The molecular structure and dosage of acetals have different effects on the mechanical properties. It can be found from Fig. $5 \mathrm{c}$, PVAC significantly reduced the Young's modulus more than $50 \%$, from 1.03 MPa of control sample to a steady level (about $0.45 \mathrm{MPa}$ ) in the whole range of dosage. On the contrary, PVB enhanced Young's modulus significantly at low dosage (less than $1 \mathrm{wt} \%)$. The maximum of Young's modulus increased 
about $67 \%$ at $0.1 \mathrm{wt} \%$ content of PVB. At higher PVB contents ( $1 \mathrm{wt} \%, 5 \mathrm{wt} \%, 10 \mathrm{wt} \%$ ), the Young's modulus decreased to the similar level as PCL/PVAC samples. For materials with very low glass transition temperature, the modulus of linear viscoelastic zone is very important to ensure the stability of the products. Therefore, the improvement in Young's modulus is of great significance for PCL in high load applications, such as stent or scaffold.

As shown in Fig. 5d, crystallinity and crystal morphology have little effect on the yield strength of PCL. At lower contents of polyvinyl acetals ( $\leq 1 \mathrm{wt} \%$ ), the tensile strength and elongation at break of PVB added samples were a little higher than that of PVAC added sample, but they were comparable with the control sample. When the mass fractions beyond 1\%, both PVB and PVAC made the tensile strength and elongation at break decrease obviously (Fig. 5e and f).

It is generally accepted that the larger the crystalline size, the lower the mechanical properties. Quite to the contrary, herein, polyvinyl acetals enlarged the spherulite size of PCL to 160-200 $\mu \mathrm{m}$ and PVB enhanced its Young's modulus. Considering that the samples in the nucleation analysis were program cooled $\left(10^{\circ} \mathrm{C} \mathrm{min}^{-1}\right)$, while the samples used for mechanical property test were rapidly cooled (the melt at $100{ }^{\circ} \mathrm{C}$ was injected directly into a mould at $25^{\circ} \mathrm{C}$ ), the injection samples were also analysed

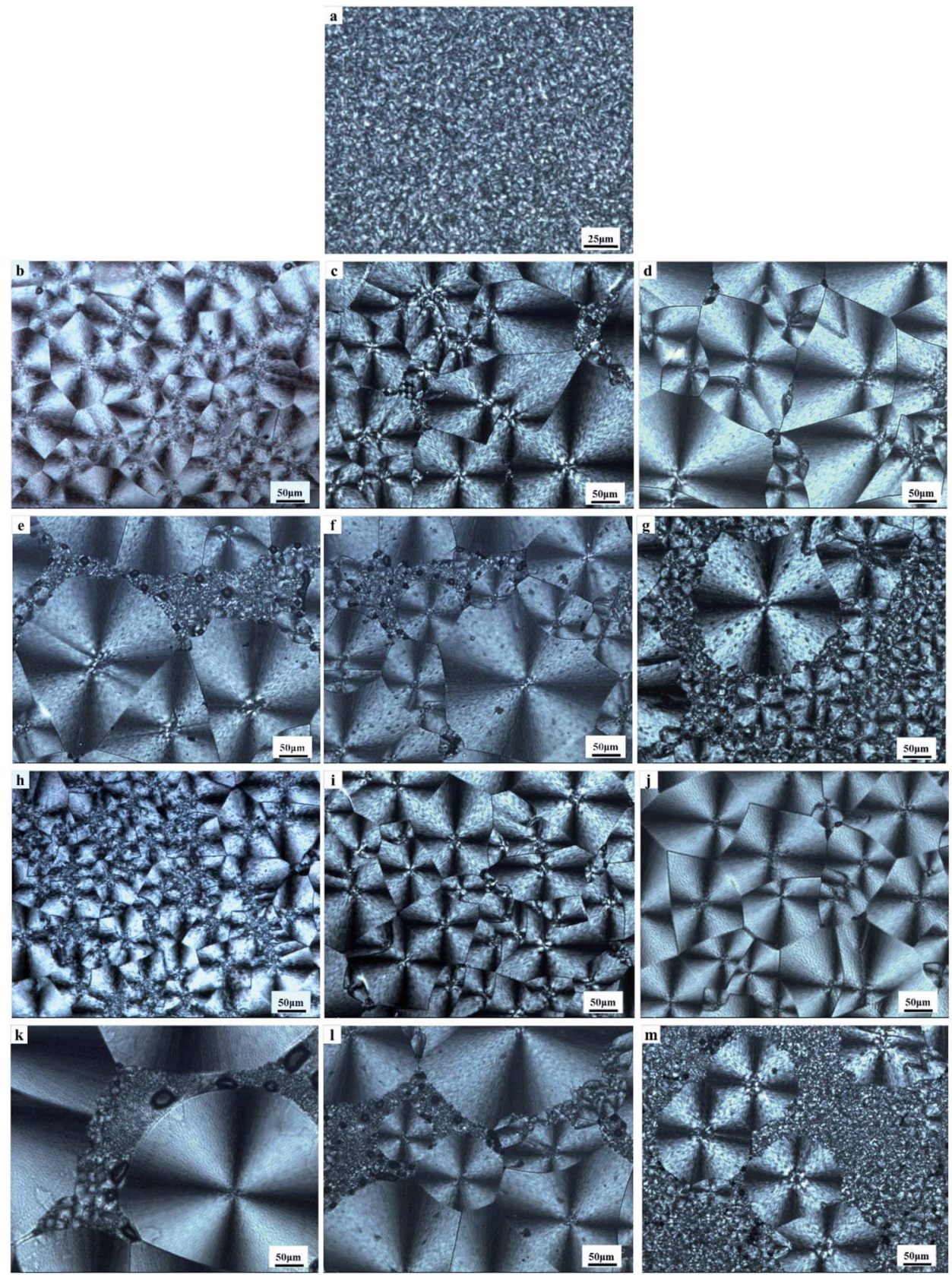

Fig. 4 POM photomicrograph of PCL undergone a program cooling $\left(10^{\circ} \mathrm{C} \mathrm{min}{ }^{-1}\right)$ : (a) control PCL; (b) $-(\mathrm{g}) \mathrm{PCL}$ with 0.1 wt\%, 0.3 wt\%, 0.7 wt\%, $1.0 \mathrm{wt} \%, 5.0 \mathrm{wt} \%$ and $10.0 \mathrm{wt} \%$ PVAC; (h)-(m) PCL with $0.1 \mathrm{wt} \%, 0.3 \mathrm{wt} \%, 0.7 \mathrm{wt} \%, 1.0 \mathrm{wt} \%, 5.0 \mathrm{wt} \%$ and $10.0 \mathrm{wt} \%$ PVB. 
by DSC, and the crystalline morphology of samples under simulated injection cooling conditions was observed. The details were discussed in the following section.

\section{Effect of cooling rate on crystallization of PCL}

Fig. 6 shows the crystallinities of PCL which undergone program cooling $\left(10^{\circ} \mathrm{C} \mathrm{min}^{-1}\right)$ or quenched (injection moulded) procedure, and the variation of crystallinity and melting temperature of stretched PCL. As seen from Fig. 6a, the crystallinities of injection samples are almost above $45 \%$, which is much higher than that of programmed cooling samples. This indicated that fast cooling is beneficial to increase crystallinity. Fig. $6 \mathrm{~b}$ and $\mathrm{c}$ show the different crystallization parameters of injection sample before and after tensile test. Stretching is beneficial to the orientation and regular arrangement of PCL chains. Thus, the crystallinity was promoted, e.g. the $X_{c}^{*}$ of control samples increased from $45.8 \%$ to $52 \%$ (Fig. 6b). When the mass fraction of polyvinyl acetals was less than $1 \%$, the melting temperatures of stretched samples had an increase of more than $2{ }^{\circ} \mathrm{C}$ (Fig. 6c). The root cause for this result is the extremely low glass transition temperature of PCL, which makes the orientation and rearrangement of molecules possible at room temperature. During fragmentation of the lamellae, the chains escaped from the initial chain-folded lamellae into the amorphous region, became extended, and easily crystallized into new chain-extended lamellae. ${ }^{47}$
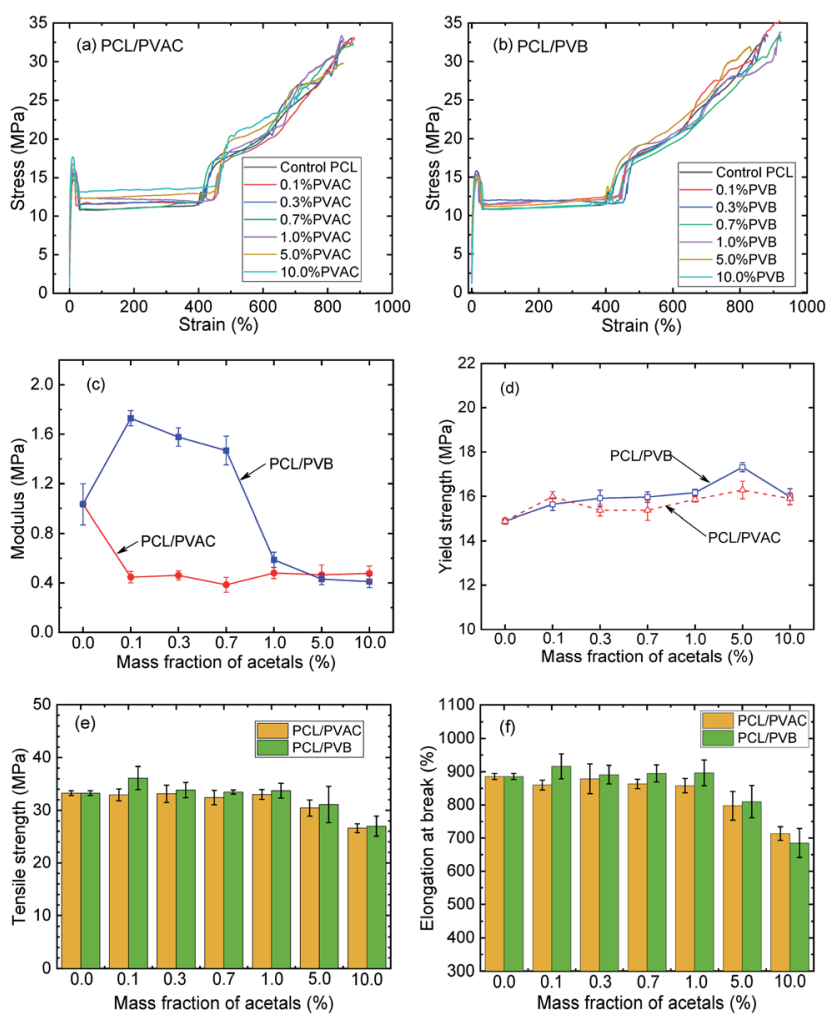

Fig. 5 Effects of acetals on mechanical properties of PCL: (a) stressstrain curves of PCL/PVAC; (b) stress-strain curves of PCL/PVB; (c) modulus; (d) yield strength; (e) tensile strength; ( $f$ ) elongation at break.
POM observation also confirmed the clear distinction between program cooling samples $\left(10^{\circ} \mathrm{C} \min ^{-1}\right)$ and the fast cooling sample which undergone a simulated cooling conditions of the injection process (Fig. 7).

Compared with the programmed cooling sample in Fig. 4, the spherulite size of the fast cooling samples decreased significantly at low content of polyvinyl acetals. For example, the grain size decreased from $100 \mu \mathrm{m}$ to about $20 \mu \mathrm{m}$ at $0.1 \mathrm{wt} \%$ polyvinyl acetals. When the content of polyvinyl acetals was less than $1 \mathrm{wt} \%$, the grain size of PVB nucleated samples was more uniform and no fine grains appeared, which was consistent with POM results of program cooling samples.

Combining the crystallization behaviour and crystal morphology, we propose that the initial distortion during tensile test was originated from amorphous regions and small spherulite. All the samples containing PVAC and samples with high mass fraction of PVB $(1 \%, 5 \%, 10 \%)$ are tend to deform firstly from the "weak region", i.e. fine grains, resulting in the decrease of Young's modulus. However, the samples with lower content PVB (less than 1\%) content have uniform grain size and no fine grain aggregation area, which ensured macroscopic uniformity and correspondingly increased modulus.

\section{Crystallization kinetics of PCL}

Avrami model. The Avrami model is generally used to describe the isothermal crystallization process and the equation is as follow: :8-50 $^{40}$

$$
X(t)=1-\exp \left(-K t^{n}\right)
$$

where $X(t)$ is the crystallinity fraction of a crystallizable material at time $t ; n$ is the Avrami index, which depends on the nucleation and growth mechanism, and $K$ is the crystallization rate
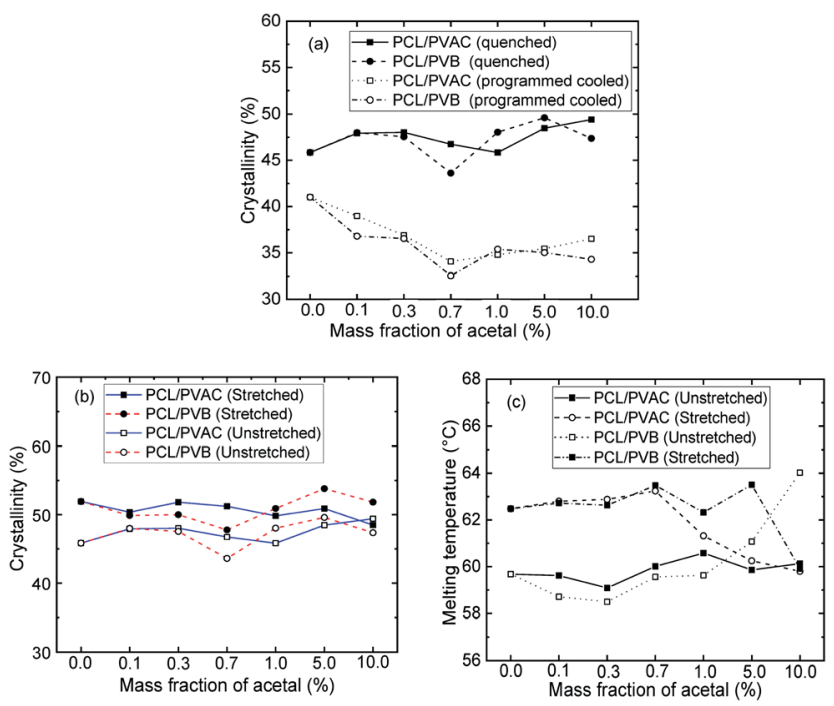

Fig. 6 DSC analysis of program cooling and injection moulded specimens. (a) Crystallinity calculated from the melting enthalpy $\left(X_{c}^{*}\right)$ of program cooling $\left(10^{\circ} \mathrm{C} \mathrm{min}^{-1}\right)$ and injection moulded samples; (b) $X_{\mathrm{c}}^{*}$ and (c) melting temperature of injection sample (quenched). 
constant and temperature dependent. Avrami equation can also be transformed into the linear form of eqn (4):

$$
\log (-\ln (1-X(t)))=\log K+n \log t
$$

By plotting $\log (-\ln (1-X(t)))$ versus $\log t$, a series of lines with slope $n$ and intercept $\log K$ can be obtained. To apply the Avrami model to depicting non-isothermal crystallization, Jeziorny $^{51}$ corrected the $\log K$ by introducing the cooling rate, $\Phi$ :

$$
\log K_{\mathrm{c}}=\frac{\log K}{\Phi}
$$

The half-crystallization time $t_{1 / 2}$ can be obtained from eqn (6):

$$
t_{1 / 2}=\left(\frac{\ln 2}{K_{\mathrm{c}}}\right)^{\frac{1}{n}}
$$

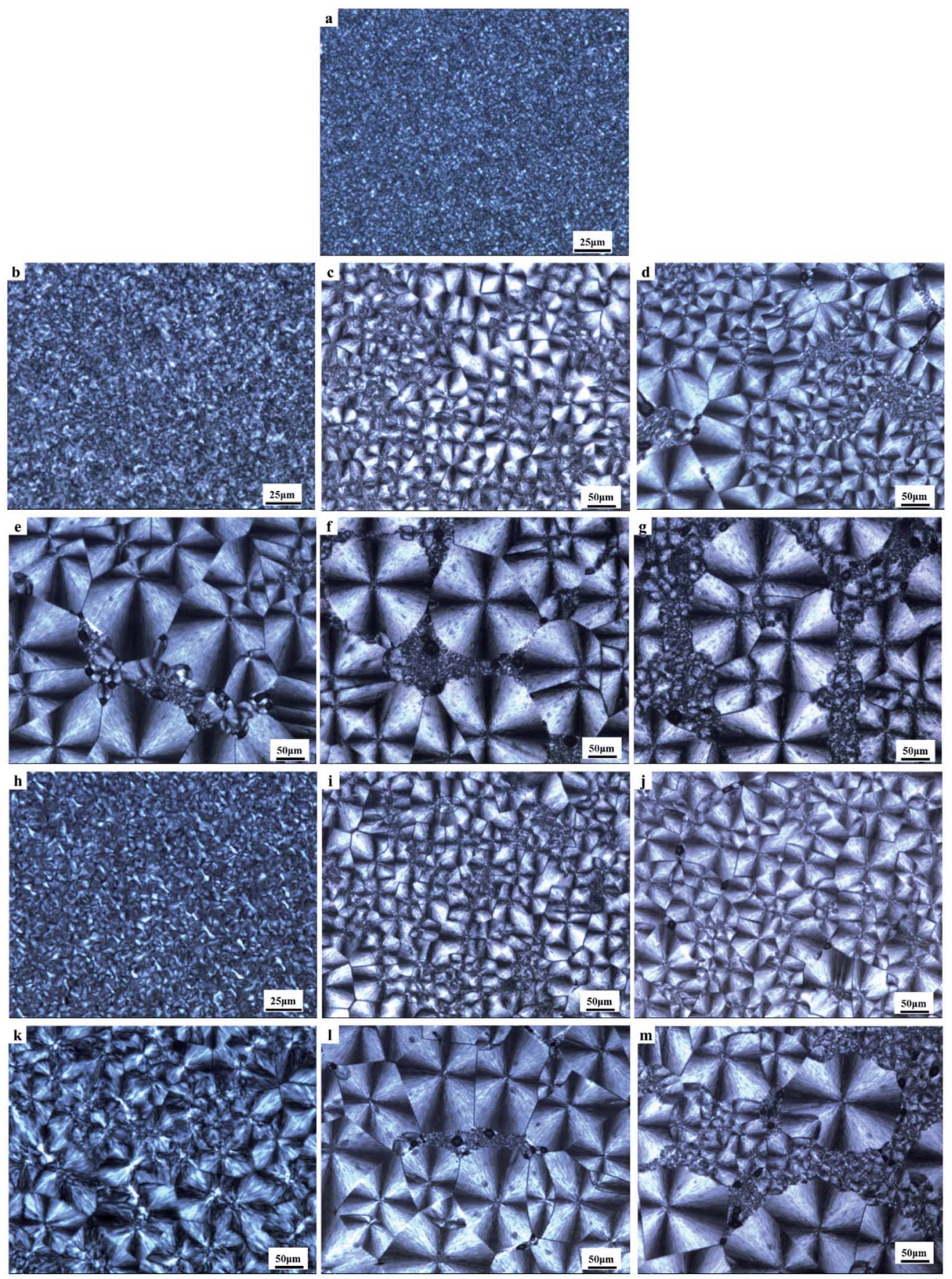

Fig. 7 POM microphotographs of PCL undergo a fast cooling process: (a) control PCL; (b) - (g) PCL with 0.1 wt\%, 0.3 wt\%, 0.7 wt\%, 1.0 wt\%, 5.0 wt\% and 10.0 wt\% PVAC; (h)-(m) PCL with 0.1 wt\%, 0.3 wt\%, 0.7 wt\%, 1.0 wt\%, 5.0 wt\% and 10.0 wt\% PVB. 

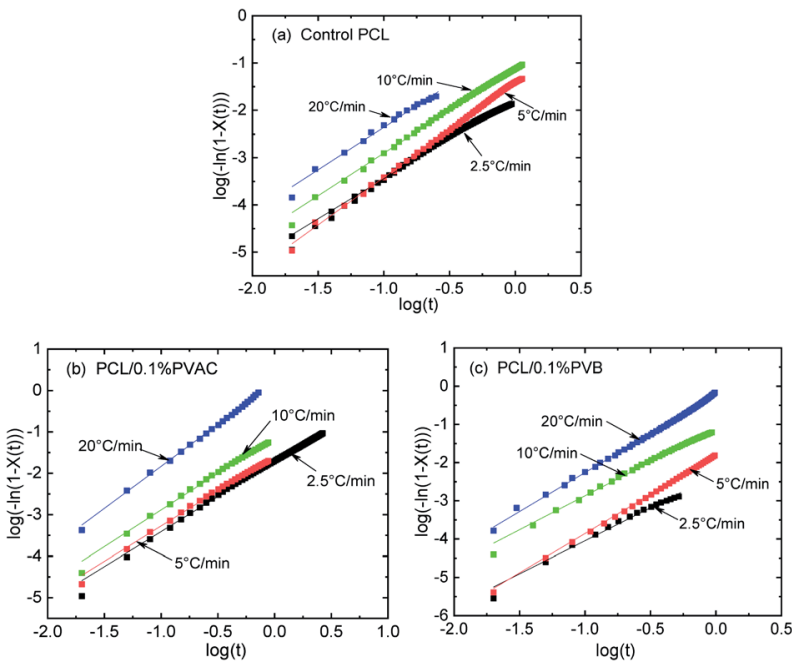

Fig. 8 Avrami plots under various cooling rates for control and nucleated PCL.

Fig. 8 gives the linear relationship of $\log (-\ln (1-X(t)))$ versus $\log t$ of control and nucleated PCL at various cooling rates, where the data of intermediate crystallization were used so as to apply the modified Avrami model. There is no deviation for all samples, indicating that the modified Avrami model is suitable to describe the non-isothermal crystallization kinetics of PCL. The crystallization kinetics parameters derived from Fig. 8 are summarized in Table 2 . With the increase of cooling rate, halfcrystallization time $\left(t_{1 / 2}\right)$ is shortened, while the non-isothermal crystallization rate constant $\left(K_{\mathrm{c}}\right)$ is increased. This indicates that the crystallization rate increases with the cooling rate, which is consistent with the above discussion about the effect of cooling rate on PCL crystallization.

Tobin model. Considering the effect of growth site impingement on crystallization, Tobin model ${ }^{52-55}$ was used to describe the nucleation and spherulite growth process. The expression of relative crystallinity, $X(t)$, function of time, $t$, is

Table 2 Non-isothermal crystallization kinetic parameters of PCL (modified Avrami model)

\begin{tabular}{lrlll}
\hline & \multicolumn{1}{l}{$\Phi$} & & & \\
Sample & $\left({ }^{\circ} \mathrm{C} \mathrm{min}^{-1}\right)$ & $n$ & $K_{\mathrm{c}}$ & $t_{1 / 2}(\mathrm{~min})$ \\
\hline Control PCL & 2.5 & 1.697 & 0.200 & 1.643 \\
& 5.0 & 2.014 & 0.525 & 1.057 \\
& 10.0 & 1.804 & 0.777 & 0.989 \\
$0.1 \%$ PVAC & 20.0 & 1.801 & 0.938 & 0.985 \\
& 2.5 & 1.688 & 0.205 & 1.628 \\
& 5.0 & 1.703 & 0.485 & 1.074 \\
$0.1 \%$ PVB & 10.0 & 1.767 & 0.773 & 0.989 \\
& 20.0 & 2.031 & 1.023 & 0.981 \\
& 2.5 & 1.722 & 0.118 & 2.032 \\
& 5.0 & 2.048 & 0.435 & 1.098 \\
& 10.0 & 1.775 & 0.777 & 0.989 \\
& 20.0 & 2.042 & 0.975 & 0.983
\end{tabular}

Table 3 Tobin crystallization rate constant $\left(K_{T}\right)$ and exponent $\left(n_{T}\right)$ derived from the nonlinear fitting

\begin{tabular}{|c|c|c|c|c|c|}
\hline \multirow[b]{2}{*}{ Sample } & & \multicolumn{4}{|c|}{$\Phi /{ }^{\circ} \mathrm{C} \min ^{-1}$} \\
\hline & & 2.5 & 5 & 10 & 20 \\
\hline \multirow[t]{2}{*}{ Control PCL } & $K_{\mathrm{T}}$ & 0.40 & 0.54 & 0.74 & 0.93 \\
\hline & $n_{\mathrm{T}}$ & 5.89 & 7.70 & 8.53 & 8.27 \\
\hline \multirow[t]{2}{*}{ 0.1\% PVAC } & $K_{\mathrm{T}}$ & 0.27 & 0.46 & 0.75 & 0.94 \\
\hline & $n_{\mathrm{T}}$ & 8.12 & 5.73 & 7.36 & 7.83 \\
\hline \multirow[t]{2}{*}{$0.1 \%$ PVB } & $K_{\mathrm{T}}$ & 0.28 & 0.49 & 0.70 & 1.23 \\
\hline & $n_{\mathrm{T}}$ & 6.78 & 6.85 & 8.39 & 7.57 \\
\hline
\end{tabular}

where $K_{\mathrm{T}}$ and $n_{\mathrm{T}}$ are the Tobin crystallization rate constants and exponents, respectively.

The curves of relative crystallinity versus time during nonisothermal crystallization of PCL at different cooling rate are shown in Fig. 9. The typical "S" curve shifts to the left with the increase of cooling rate. Tobin model well describes the relationship of relative crystallization and time at higher cooling rate $\left(10{ }^{\circ} \mathrm{C} \mathrm{min}{ }^{-1}\right.$ and $\left.20{ }^{\circ} \mathrm{C} \mathrm{min}^{-1}\right)$. Under lower cooling rate $\left(2 .{ }^{\circ} \mathrm{C} \mathrm{min}^{-1}\right.$ and $\left.5{ }^{\circ} \mathrm{C} \mathrm{min}^{-1}\right)$, slight deviation appears at the beginning and end of crystallization.

The Tobin crystallization rate constant and exponent are list in Table 3. The rate constant of crystallization increases with the cooling rate, and the values are similar at the same cooling rate except the rate of $2.5^{\circ} \mathrm{C} \mathrm{min}^{-1}$. The Tobin exponent of control and nucleated PCL falls in the range of 5.7-8.4, and is larger than the modified Avrami index.

\section{Conclusions}

As a lineal aliphatic polyester, PCL has a very low glass transition temperature, and the flexible polymer chains are easily 
entangled, which is unfavourable to crystallization. Interestingly, benefit from the disentangled effect of melt shearing (mixing), the crystallization temperature (increased by $7.7^{\circ} \mathrm{C}$ ) and crystallinity of control PCL were improved obviously. This discovery provides a new approach to improve the crystallization capacity of PCL.

Using polyvinyl acetals as macromolecular nucleating agent, we investigated the non-isothermal crystallization behaviour, crystalline morphology and mechanical properties of PCL. The blends showed good compatibility in the acetal contents range from $0.1 \%$ to $0.7 \%$. When the nucleating agent contents were beyond $0.7 \%$ (1-10 wt\%), microphase separation occurred. PVAC and PVB significantly increased the spherulite size of PCL and reduce the crystallization temperature. Compared with PVAC, PVB has more powerful heterogeneous nucleation effect due to the longer side groups. When the contents were less than $1 \mathrm{wt} \%$, PVB inhibited the formation of fine grains which was closely related with the initial distortion during the tensile test; the fine grains completely disappeared under fast cooling and the Young's modulus increased dramatically by $67 \%$. Both the modified Avrami and Tobin models well described the nonisothermal crystallization of PCL, and the crystallization parameters had no significant change. This means that the addition of nucleating agents has no effect on the crystallization kinetics of PCL.

\section{Conflicts of interest}

There are no conflicts to declare.

\section{Acknowledgements}

The authors specially acknowledge the support by National Natural Science Foundation of China $(51473007,21606005$, 31570575), Fundamental Research Funds of Beijing Technology and Business University (19005902015) and Natural Science Foundation of Beijing Municipality (2192016).

\section{References}

1 D. Goldberg, J. Environ. Polym. Degrad., 1995, 3, 61-67.

2 O. Persenaire, M. Alexandre, P. Degee and P. Dubois, Biomacromolecules, 2001, 2, 288-294.

3 M. A. Woodruff and D. W. Hutmacher, Prog. Polym. Sci., 2010, 35, 1217-1256.

4 L. Qiu, B. Hu, H. Chen, S. Li, Y. Hu, Y. Zheng and X. Wu, Int. J. Nanomed., 2015, 10, 1415-1423.

5 X. Tang, Y. Lyu, D. Xie, A. Li, Y. Liang and D. Zheng, J. Biomed. Nanotechnol., 2018, 14, 396-403.

6 N. Upho, B. Tangtrakulwanich, P. Pripatnanont, P. Thitiwongsawet and N. Ingviya, J. Pharm. Innov., 2015, 10, 211-221.

7 D. de Cassan, S. Sydow, N. Schmidt, P. Behrens, Y. Roger, A. Hoffmann, A. L. Hoheisel, B. Glasmacher, R. Hansch and H. Menzel, Colloids Surf., B, 2018, 163, 309-320.

8 V. Tamboli, G. P. Mishra and A. K. Mitra, Colloid Polym. Sci., 2013, 291, 1235-1245.
9 M. Gumusderelioglu, F. B. Kaya and I. G. Beskardes, J. Colloid Interface Sci., 2011, 358, 444-453.

10 V. Guarino, F. Veronesi, M. Marrese, G. Giavaresi, A. Ronca, M. Sandri, A. Tampieri, M. Fini and L. Ambrosio, Biomed. Mater., 2016, 11, 015018.

11 L. M. He, B. Liu, X. P. Guan, G. Y. Xie, S. S. Liao, D. P. Quan, D. Z. Cai, J. Lu and S. Ramakrishna, Eur. Cells Mater., 2009, 18, 63-74.

12 H. Y. Mi, X. Jing, E. Yu, X. Wang, Q. Li and L. S. Turng, J. Mech. Behav. Biomed. Mater., 2018, 78, 433-441.

13 M. J. Liu, S. C. Chen, K. K. Yang and Y. Z. Wang, RSC Adv., 2015, 5, 42162-42173.

14 M.-H. Huang, S. Li and M. Vert, Polymer, 2004, 45, 86758681.

15 J. M. Ugartemendia, M. E. Munoz, A. Santamaria and J. R. Sarasua, J. Mech. Behav. Biomed. Mater., 2015, 48, 153163.

16 W. Z. Yuan, X. Z. Tang, X. B. Huang and S. X. Zheng, Polymer, 2005, 46, 1701-1707.

17 I. Kelnar, J. Kratochvil, L. Kapralkova, A. Zhigunov and M. Nevoralova, J. Mech. Behav. Biomed. Mater., 2017, 71, 271-278.

18 W. Q. Han, X. Liao, Q. Yang, G. X. Li, B. He, W. L. Zhu and Z. H. Hao, RSC Adv., 2017, 7, 22515-22523.

19 S. X. Li, C. N. Ye, G. D. Zhao, M. J. Zhang and Y. L. Zhao, J. Polym. Sci., Part A: Polym. Chem., 2012, 50, 3135-3148.

20 W. W. Wang, L. L. Chang, X. Li, Y. L. Wu, J. F. Xing, L. D. Deng and A. J. Dong, Soft Matter, 2012, 8, 1575-1583.

21 C. He, J. Sun, J. Ma, X. Chen and X. Jing, Biomacromolecules, 2006, 7, 3482-3489.

22 P. Zhang, H. Y. Huang, Y. Chen, S. Yu, C. Krywka, S. K. Vayalil, S. V. Roth and T. B. He, Chin. J. Polym. Sci., 2014, 32, 1188-1198.

23 J. A. Pena, S. J. Gutierrez, J. C. Villamil, N. A. Agudelo and L. D. Perez, Mater. Sci. Eng., C, 2016, 58, 60-69.

24 S. N. Xia, Y. Shen, Y. Q. Zhou, P. F. Yao, Q. S. Liu and B. Y. Deng, Colloid Polym. Sci., 2018, 296, 1667-1677.

25 Z. B. Qiu, W. T. Yang, T. Ikehara and T. Nishi, Polymer, 2005, 46, 11814-11819.

26 W. Z. Yuan, J. Y. Yuan, X. B. Huang and X. Z. Tang, J. Appl. Polym. Sci., 2007, 104, 2310-2317.

27 K. J. Zhang and Z. B. Qiu, Chin. J. Polym. Sci., 2017, 35, 15171523.

28 T. Dong, Y. He, B. Zhu, K. M. Shin and Y. Inoue, Macromolecules, 2005, 38, 7736-7744.

29 T. Dong, W. H. Kai, P. J. Pan, A. Cao and Y. Inoue, Macromolecules, 2007, 40, 7244-7251.

30 J. F. Vega, J. Fernandez-Alcazar, J. V. Lopez, R. M. Michell, R. A. Perez-Camargo, B. Ruelle, J. Martinez-Salazar, M. L. Arnal, P. Dubois and A. J. Muller, J. Polym. Sci., Part B: Polym. Phys., 2017, 55, 1310-1325.

31 T. H. Zhao, K. L. Yang, R. T. Zeng, A. K. Du, M. Wang and J. B. Zeng, Ind. Eng. Chem. Res., 2016, 55, 1881-1889.

32 Q. Liu, Z. Q. Peng and D. J. Chen, Polym. Eng. Sci., 2007, 47, 460-466.

33 Q. L. Lv, C. J. Xu, D. F. Wu, Z. F. Wang, R. Y. Lan and L. S. Wu, Composites, Part A, 2017, 92, 17-26. 
34 Q. L. Lv, Z. R. Ying, D. F. Wu, Z. F. Wang and M. Zhane, Ind. Eng. Chem. Res., 2017, 56, 2746-2753.

35 H. J. Chiu, R. S. Tsai and J. M. Huang, E-Polymers, 2010, 10, 75-86.

36 J. Cai, Z. Y. Xiong, M. Zhou, J. Tan, F. B. Zeng, M. H. Ma, S. Lin and H. G. Xiong, Carbohydr. Polym., 2014, 102, 746754.

37 B. Yang, H. Ni, J. Huang and Y. Luo, Macromolecules, 2013, 47, 284-296.

38 B. Yang, S. J. Zhu, Y. Luo and J. J. Huang, J. Polym. Sci., Part B: Polym. Phys., 2017, 55, 658-672.

39 K. N. Jeong-Chang Lee, T. Ikehara and T. Nishi, Public Prod. Manag. Rev., 1997, 21, 230-250.

40 T. M. Wu, J. C. Cheng and M. C. Yan, Polymer, 2003, 44, 2553-2562.

41 Y. Nozue, R. Kurita, S. Hirano, N. Kawasaki, S. Ueno, A. Iida, T. Nishi and Y. Amemiya, Polymer, 2003, 44, 6397-6405.

42 M. R. Lostoeeo, C. A. Murphy, J. A. Cameron and S. J. Huang, Polym. Degrad. Stab., 1998, 59, 303-307.

43 J. X. Fu, Y. X. Wang, K. Z. Shen, Q. Fu and J. Zhang, J. Polym. Sci., Part B: Polym. Phys., 2019, 57, 598-606.
44 M. Trujillo, M. L. Arnal, A. J. Muller, M. A. Mujica, C. U. de Navarro, B. Ruelle and P. Dubois, Polymer, 2012, 53, 832-841.

45 G. M. Chen, T. M. Zou, L. Chen and Y. P. Huang, Asian J. Chem., 2010, 22, 5902-5912.

46 A. Toda, K. Taguchi and H. Kajioka, Polymer, 2012, 53, 17651771.

47 T. Kamal, T. J. Shin and S.-Y. Park, Macromolecules, 2012, 45, 8752-8759.

48 M. Avrami, J. Chem. Phys., 1939, 7, 1103-1112.

49 M. Avrami, J. Chem. Phys., 1940, 8, 212-224.

50 M. Avrami, J. Chem. Phys., 1941, 9, 177-184.

51 A. Jeziorny, Polymer, 1978, 19, 1142-1144.

52 M. C. Tobin, J. Polym. Sci., Part B: Polym. Phys., 1976, 14, 2253-2257.

53 M. C. Tobin, J. Polym. Sci., Part B: Polym. Phys., 1977, 15, 2269-2270.

54 G. Eder, H. Janeschitz-Kriegl and S. Liedauer, Prog. Polym. Sci., 1990, 15, 629-714.

55 G. Z. Papageorgiou, D. S. Achilias and D. N. Bikiaris, Macromol. Chem. Phys., 2007, 208, 1250-1264. 